Research article

\title{
Lichens in 50 ha permanent plot of Mudumalai Wildlife Sanctuary, Tamil Nadu, India
}

\author{
Komal K. Ingle ${ }^{1}$, Sanjeeva Nayaka ${ }^{1}$ and H. S. Suresh ${ }^{2}$ \\ ${ }^{1}$ Lichenology Laboratory, CSIR-National Botanical Research Institute, Rana Pratap Marg, \\ Lucknow-226001, India \\ ${ }^{2}$ Centre for Ecological Sciences, Indian Institute of Science, Bangalore-560012, India
}

*Corresponding Author: nayaka.sanjeeva@gmail.com

[Accepted: 25 December 2016]

\begin{abstract}
Mudumalai Wildlife Sanctuary and National Park is a protected area located in the Tamil Nadu state within the track of Western Ghats. The very popular, permanent 50 ha 'Mudumalai Forest Dynamics Plot' is situated in Compartment 17 of the Kargudi Range in the sanctuary. The sanctuary has rich diversity of vascular plants while information regarding cryptogams is scarce. Recently, $10^{\text {th }}$ plot of 50 ha plot was visited for lichen study and it was noticed that the trunks of the trees did not support any lichens. However, luxuriant growths of lichens were observed on the fallen twigs indicating their presence in the canopy. The identification of these lichens revealed the occurrence of 66 species belonging to 27 genera and 16 families. The crustose lichens are dominant in the area with 32 species which is followed by foliose with 27 species. The lichen family Physciaceae is most diverse in the plot with 6 genus and 16 species, while Pertusaria with 15 species is the most dominant genus. Among the trees growing within the plot, Terminalia crenulata harboured maximum number of 39 species of lichens. Parmotrema tinctorum, P. crinitum, Pertusaria concinna and Pyxine coralligera are the most common lichens in the plot. There are as many as 28 rare lichens in the plot with one time encounter.
\end{abstract}

Keywords: Lichenized fungi - Nilgiri Biosphere Reserve - Western Ghats - Biodiversity.

[Cite as: Ingle KK, Nayaka S \& Suresh HS (2016) Lichens in 50 ha permanent plot of Mudumalai Wildlife Sanctuary, Tamil Nadu, India. Tropical Plant Research 3(3): 694-700]

\section{INTRODUCTION}

Lichen is symbiotic association between two organisms, an alga (or cyanobacteria) and a fungus. In the world there are about 20,000 species of lichens are known to occur and India is represented by 2350 species (Singh \& Sinha 2010). Among various states Tamil Nadu is represented by maximum number of lichens with 760 species. Location of lichen rich sites such as Nilgiri and Palni Hills, and major portion of Western Ghats falling in Tamil Nadu are the reasons for lichen richness in the state. In addition the Eastern Ghats part of Tamil Nadu also has rich diversity of lichens (Nayaka et al. 2013). However, there are many interesting localities and protected areas such as 'Mudumalai Wildlife Sanctuary and National Park' in Tamil Nadu that are unexplored for the lichens.

Mudumalai Wildlife Sanctuary and National Park ( $\left.11^{\circ} 36^{\prime} \mathrm{N}, 76^{\circ} 32^{\prime} \mathrm{E}\right)$ abuts the northern flank of the Nilgiri mountain range in the Western Ghats and is contiguous with the protected areas Bandipur and Wynaad. It is also declared 'Tiger Reserve' in the recent times. The popular, permanent 50 ha 'Mudumalai Forest Dynamics Plot' is located in Compartment 17 of the Kargudi Range of the sanctuary (Fig. 1) at the transition zone between dry and moist deciduous forest. The 50 ha plot receives average rain fall of $1200 \mathrm{~mm} / \mathrm{yr}$. The flowering plants and fauna of the sanctuary including the 50 ha plot are well documented. The sanctuary has a total of 187 tree species (Suresh et al. 1996), over 200 birds, at least 17 species of amphibians, 42 species of reptiles and 35 species of mammals. The 50 ha permanent plot provides an opportunity to conduct regular vegetation dynamics, climate and several studies related to temporal and seasonal changes. The literature survey 
clearly indicates the studies on cryptogams are rare or lacking for the Mudumali Wildlife Sanctuary (Satish et al. 2007). The lichens being a sensitive to air pollution and microclimate conditions their documentation could very well supplement the climate change studies being carried out in the 50 ha plot. Recently, one of the authors (SN) paid a short visit to the sanctuary and the preliminary observation on lichen biota is presented here.

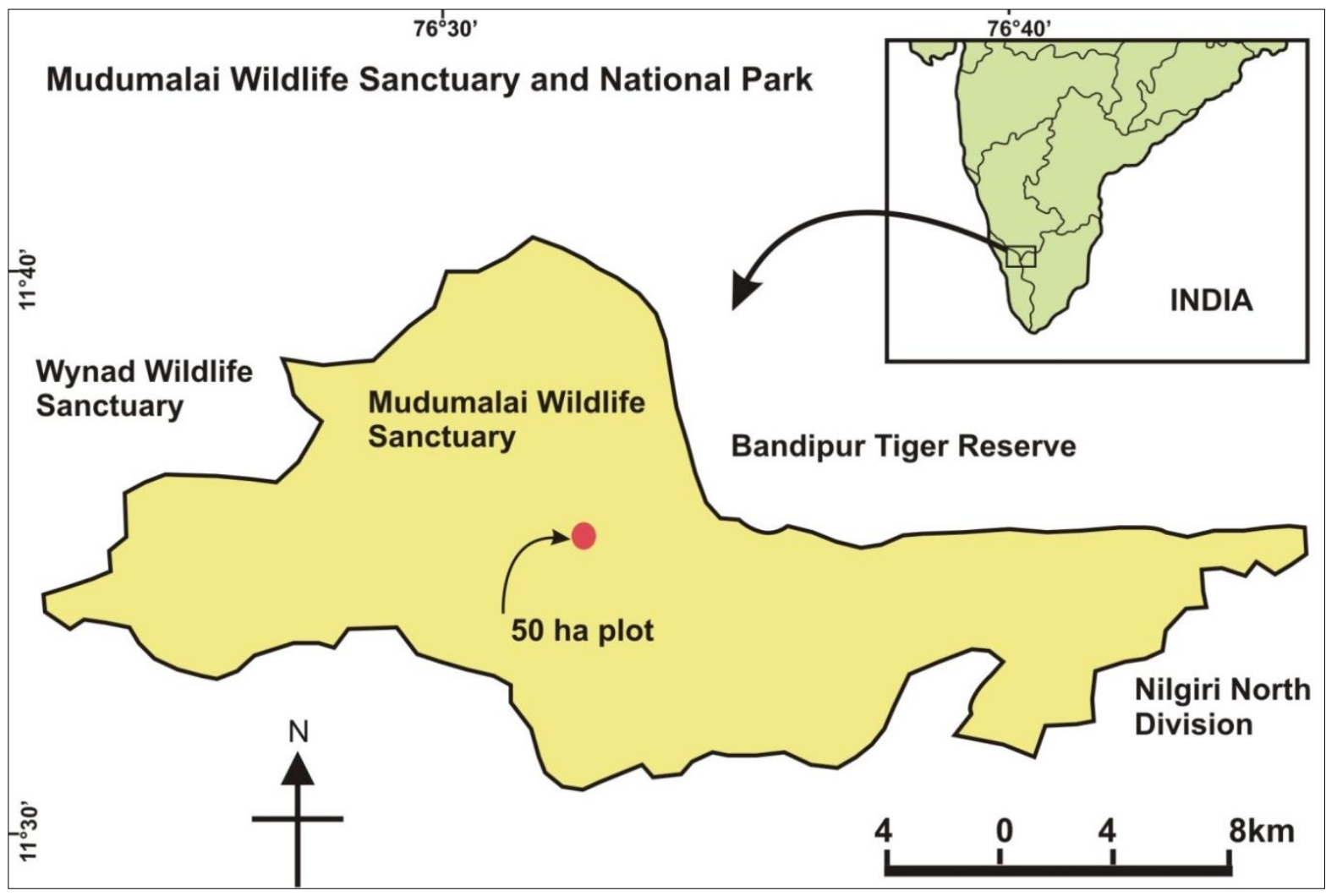

Figure 1. Map of Mudumalai Wildlife Sanctuary showing the location of 50 ha permanent Forest Dynamic Plot, from where lichens were collected.

\section{MATERIALS AND METHODS}

The $10^{\text {th }}$ plot within the 50 ha plot was surveyed for lichens and it was noticed that the trunks of the trees did not support any lichens. However, luxuriant growths of lichens were observed on the fallen twigs indicating their presence in the canopy. Such fallen twigs are gathered, cut in to smaller pieces and dried thoroughly under sun and preserved in lichen herbarium packets with detailed label. The twigs belongs to following tree species, Cassia fistula, Ficus tsjakela, Grewia tiliifolia, Lagerstroemia microcarpa, Schleichera oleosa, Syzygium cumini, Tectona grandis, and Terminalia crenulata.

The lichen specimens investigated morphologically, anatomically and chemically following recent literature (Awasthi 1991, 2007). The colour tests were performed with the routine reagent i.e. $\mathrm{K}$ (5\% potassium hydroxide), C (aqueous solution of calcium hypochloride) and $\mathrm{P}$ (paraphenylene diamene). Some lichen specimens were investigated with Thin Layer Chromatography (TLC) in solvent system A (toluene: dioxine: acetic acid) by Walker \& James (1980) method. After the identification of specimens, the samples are preserved at lichen herbarium of CSIR-National Botanical Research Institute, Lucknow (LWG). The classification of Lumbusch and Huhndorf (2007) followed for arranging species under various families.

\section{RESULTS AND DISCUSSIONS}

The identification of these lichens revealed the occurrence of 66 species belonging to 27 genera and 16 families (Table 1). The crustose lichens are dominant in the area with 32 species followed by foliose and squamulose with 27 and 5 species respectively (Fig. 2). Chrysothrix chlorina is the only leprose and Ramalina pacifica is the only fruticose lichen recorded from the $17^{\text {th }}$ ha plot. The lichen family Physciaceae is most diverse in the plot with 6 genera and 16 species while Ramalinaceae with 3 genera and 8 species and Parmeliaceae with 2 genera 8 species are other dominant families (Fig. 3). Pertusaria with 15 species is the most dominant genus and it is followed by Parmotrema (7 spp.), Heterodermia (5 spp.) and Phyllopsora (5 spp.). 


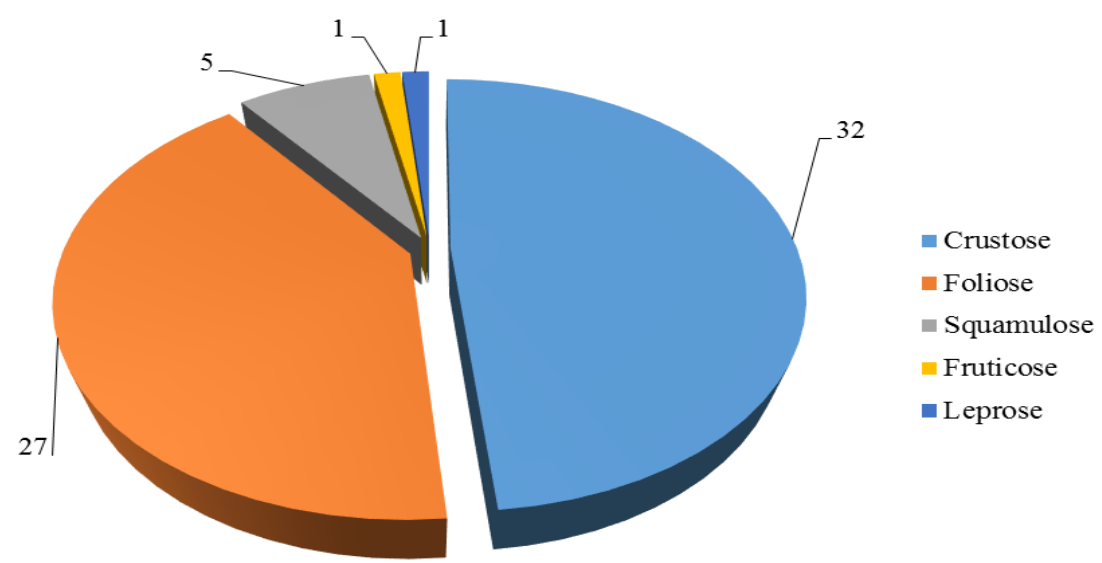

Figure 2. Pie chart showing number of species under different growth forms in the study area.

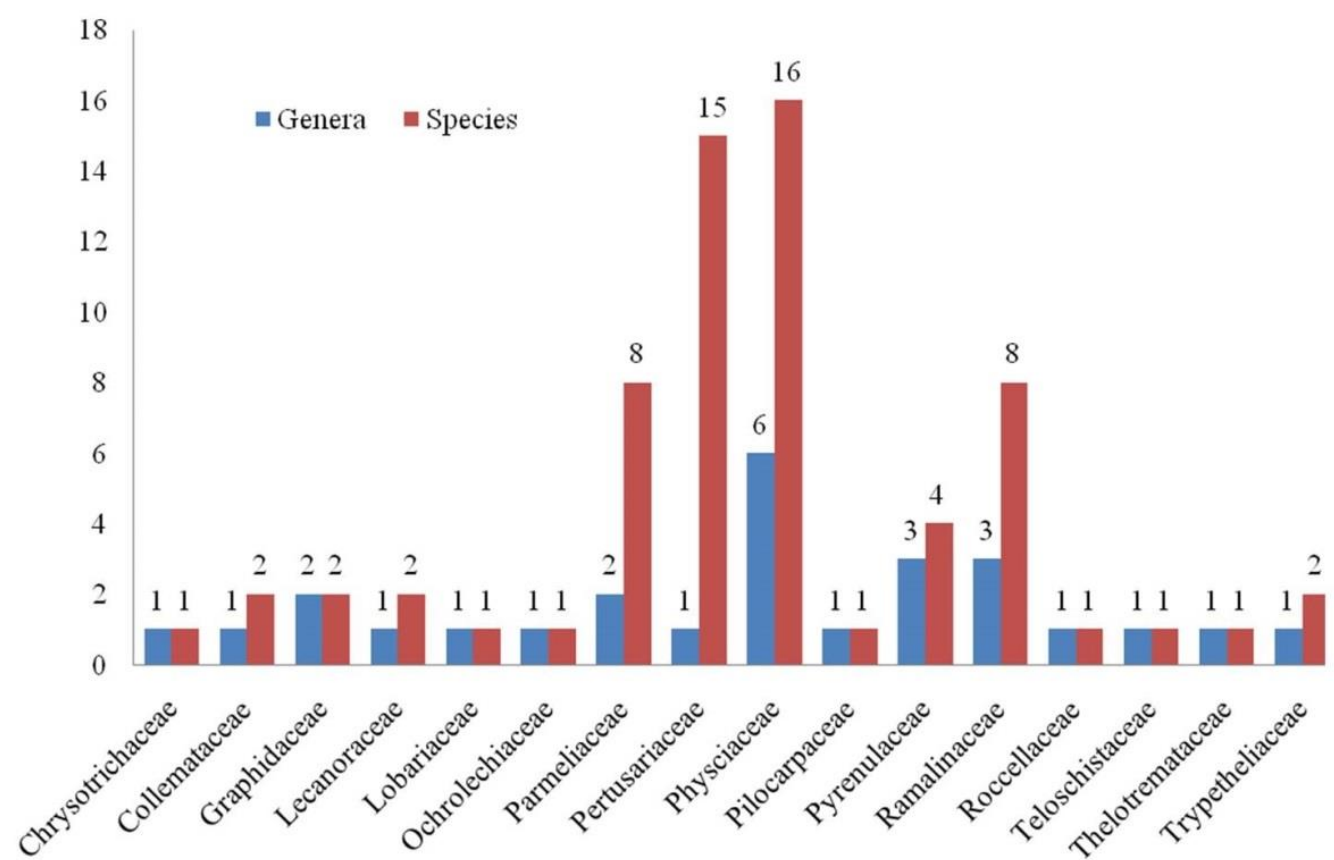

Figure 3. Bar diagram showing the diversity of species within genera and families represented in the study area.

Among the trees growing within the plot, Terminalia crenulata harboured maximum number of 39 species of lichens, followed Tectona grandis with 30 species, Syzygium cumini - 25 spp., Ficus tsjakela - 19 spp., and Lagerstroemia microcarpa - 16 spp. The tree Grewia tiliifolia harboured only one lichen species Leptogium austroamericanum (Fig. 4). Further, L. austroamericanum is rare lichen found only on this tree.

Table 1. List of lichens recorded from $10^{\text {th }}$ plot of 50 ha plot of Mudumalai Wildlife Sanctuary and their distribution on various tree species.

\begin{tabular}{llllllllllll}
\multirow{2}{*}{ Lichen taxa } & \multirow{2}{*}{ GF } & \multicolumn{1}{c}{ Tree species } & & & & \\
& & & & 2 & 3 & 4 & 5 & 6 & 7 & 8 &
\end{tabular}

\begin{tabular}{|c|c|c|c|c|c|c|c|c|c|c|}
\hline \multicolumn{11}{|l|}{ Chrysotrichaceae } \\
\hline 1. Chrysothrix chlorina (Ach.) J.R. Laundon & $\mathrm{L}$ & - & - & - & - & - & - & - & + & Common \\
\hline \multicolumn{11}{|l|}{ Collemataceae } \\
\hline Leptogium austroamericanum (Malme) C.W. Dodge & $\mathrm{F}$ & - & - & + & - & - & - & - & - & Rare \\
\hline 3. L. cyanescens (Rabenh.) Körb. & $\mathrm{F}$ & - & - & - & - & - & - & + & + & Common \\
\hline \multicolumn{11}{|l|}{ Graphidaceae } \\
\hline Diorygma junghuhnii (Mont. \& Bosch) Kalb \& al. & $\mathrm{C}$ & - & - & - & - & - & - & + & - & Rare \\
\hline Graphis nigroglauca Leight. & $\mathrm{C}$ & - & - & - & - & - & + & + & - & Common \\
\hline \multicolumn{11}{|l|}{ Lecanoraceae } \\
\hline 6. Lecanora helva Stizenb. & $\mathrm{C}$ & - & - & - & - & - & + & - & + & Common \\
\hline 7. L. perplexa Brodo & $\mathrm{C}$ & + & + & - & - & - & + & + & + & Most common \\
\hline
\end{tabular}




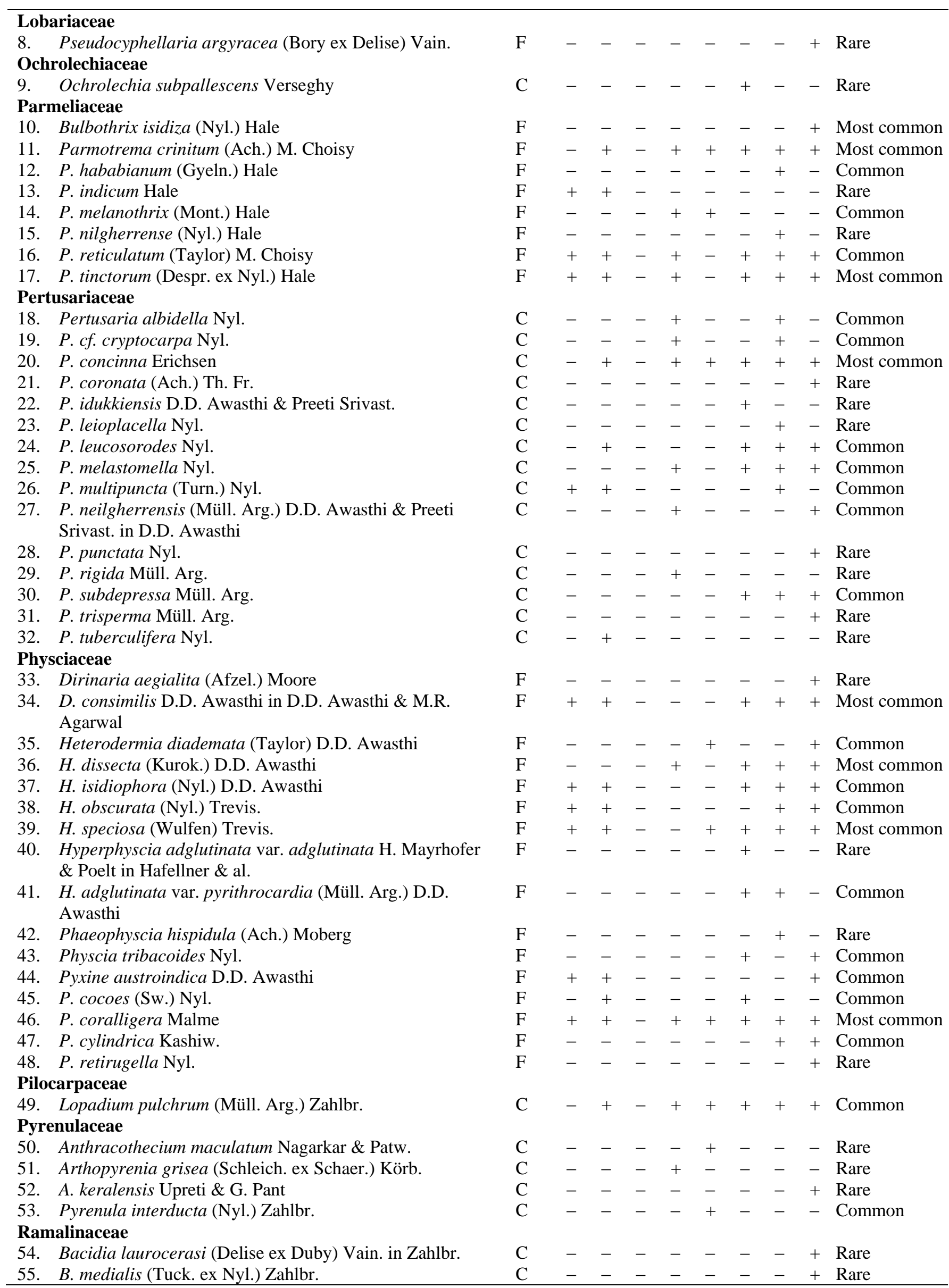




\begin{tabular}{|c|c|c|c|c|c|c|c|c|c|c|}
\hline $\begin{array}{l}\text { 56. Phyllopsora corallina var. subglaucella G.K. Mishra, } \\
\text { Upreti \& Nayaka }\end{array}$ & $\mathrm{S}$ & - & - & - & - & - & + & - & + & Common \\
\hline 57. Phyllopsora isidiotyla (Vain.) Riddle & $\mathrm{S}$ & - & - & - & + & - & - & - & - & Rare \\
\hline 58. P. kalbii Brako & $\mathrm{S}$ & - & - & - & - & + & - & - & - & Rare \\
\hline 59. P. mauritiana (Taylor) Gotth. Schneid & $\mathrm{S}$ & - & - & - & + & - & - & - & - & Rare \\
\hline 60. P. nemoralis Timdal \& Krog & S & - & - & - & - & - & + & - & + & Rare \\
\hline $\begin{array}{l}\text { 61. Ramalina pacifica Asahina } \\
\text { Roccellaceae }\end{array}$ & $\mathrm{Fr}$ & - & - & - & - & - & - & + & - & Rare \\
\hline $\begin{array}{l}\text { 62. Opegrapha bengalensis Upreti \& Ajay Singh } \\
\text { Teloschistaceae }\end{array}$ & $\mathrm{C}$ & - & - & - & - & - & - & - & + & Rare \\
\hline $\begin{array}{l}\text { 63. Caloplaca bassiae (Willd. ex Ach.) Zahlbr. } \\
\text { Thelotremataceae }\end{array}$ & $\mathrm{C}$ & - & - & - & - & + & + & + & + & Most common \\
\hline $\begin{array}{l}\text { 64. Myriotrema rugiferum (Harm.) Hale } \\
\text { Trypetheliaceae }\end{array}$ & $\mathrm{C}$ & - & - & - & - & - & - & - & + & Common \\
\hline 65. Trypethelium flavocinereum Makhija \& Patw. & $\mathrm{C}$ & - & + & - & - & - & - & + & - & Common \\
\hline 66. T. tropicum (Ach.) Müll. Arg. & $\mathrm{C}$ & - & + & - & - & - & - & - & + & Common \\
\hline
\end{tabular}

Note: $\mathrm{GF}=$ Growth Form, $\mathrm{C}=$ Crustose, $\mathrm{F}=$ Foliose, $\mathrm{Fr}=$ Fruticose, $\mathrm{S}=$ Squamulose, 1 = Cassia fistula, $2=$ Ficus tsjakela, $3=$ Grewia tiliifolia, $4=$ Lagerstroemia microcarpa, $5=$ Schleichera oleosa, $6=$ Syzygium cumini, $7=$ Tectona grandis, $8=$ Terminalia crenulata: $-=$ Absent, $+=$ Present.

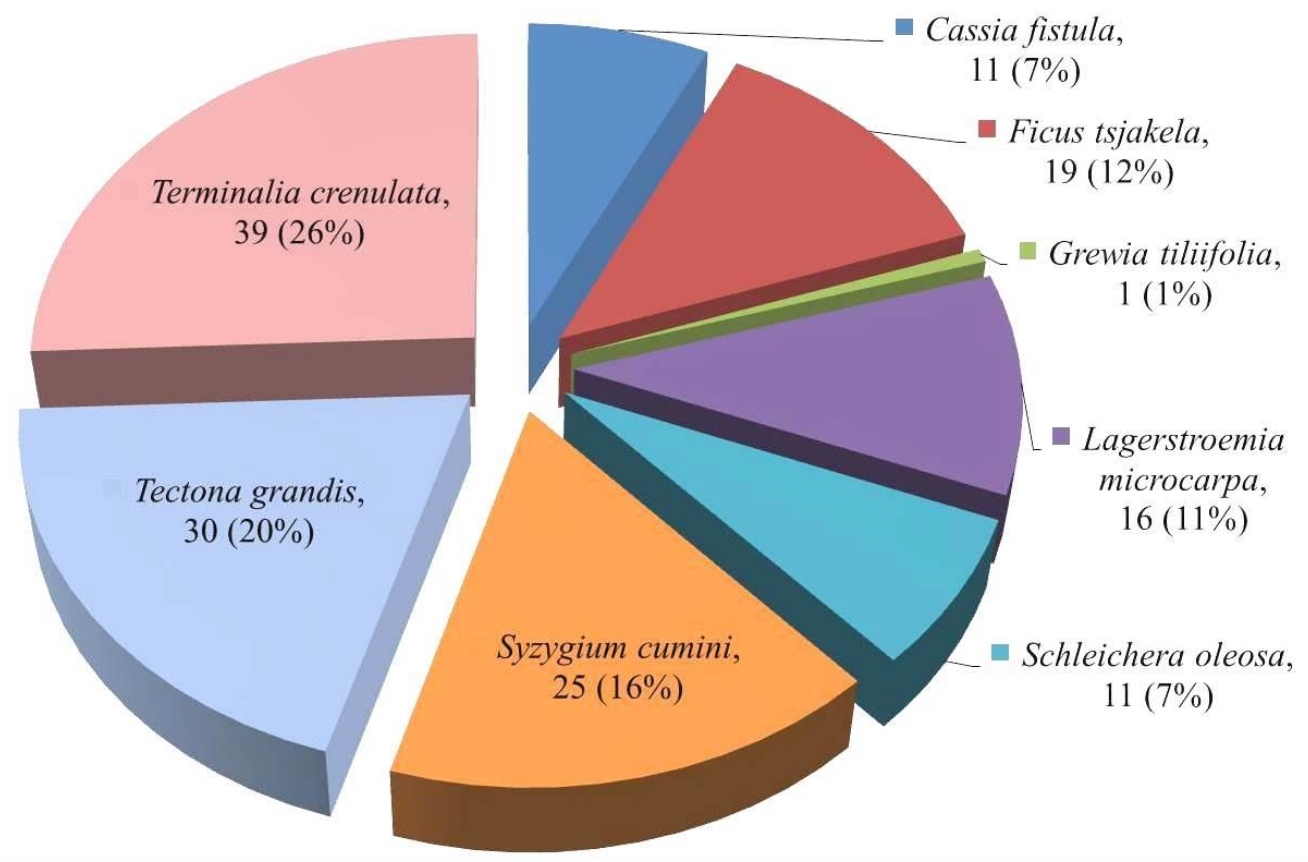

Figure 4. Pie chart showing number of lichen species on different host plant in the study area.

Parmotrema tinctorum, P. crinitum, Pertusaria concinna, and Pyxine coralligera, are the most common lichens in the plot (Fig. 5). Ten very common lichens as many as 28 rare lichens with one time in the plot are marked in the table 1. Some prominent examples of rare lichens are Arthopyrenia keralensis, Diorygma junghuhnii, Ochrolechia subpallescens, Parmotrema indicum, Phaeophyscia hispidula, Pseudocyphellaria argyracea, and Ramalina pacifica.

Mudumalai has high density of furgivorous mammals causing damage to woody plants through their feeding activity. Asian elephants are the most notorious animals that destroy the trees by peeling off their bark and also by felling. Mudumalai has a long history of human settlement (Hockings 1989, Prabhakar 1994). Huntersgatherer societies such as the Kurubas, Irulas, Paniys, and Kotas have inhabited this region for several centuries, but their number was always fluctuating due to outbreaks of disease and strife. In the recent times due better medical facilities the population size has increased and they are invading the forest area for settlement, hence anthropogenic disturbance to the forest is inevitable. The anthropogenic disturbance involves mainly logging, systematic extraction of timber (Ranganathan 1941) and collection of non-timber forest products. However, the major threat to the forest in general and to the lichen in particular is frequent fires during month dry season as the grasses are desiccated and highly flammable. Intense and widespread fires usually burn the understory vegetation and tree trunks spreading up to a considerable height. The fire completely destroys the epiphytic www.tropicalplantresearch.com 

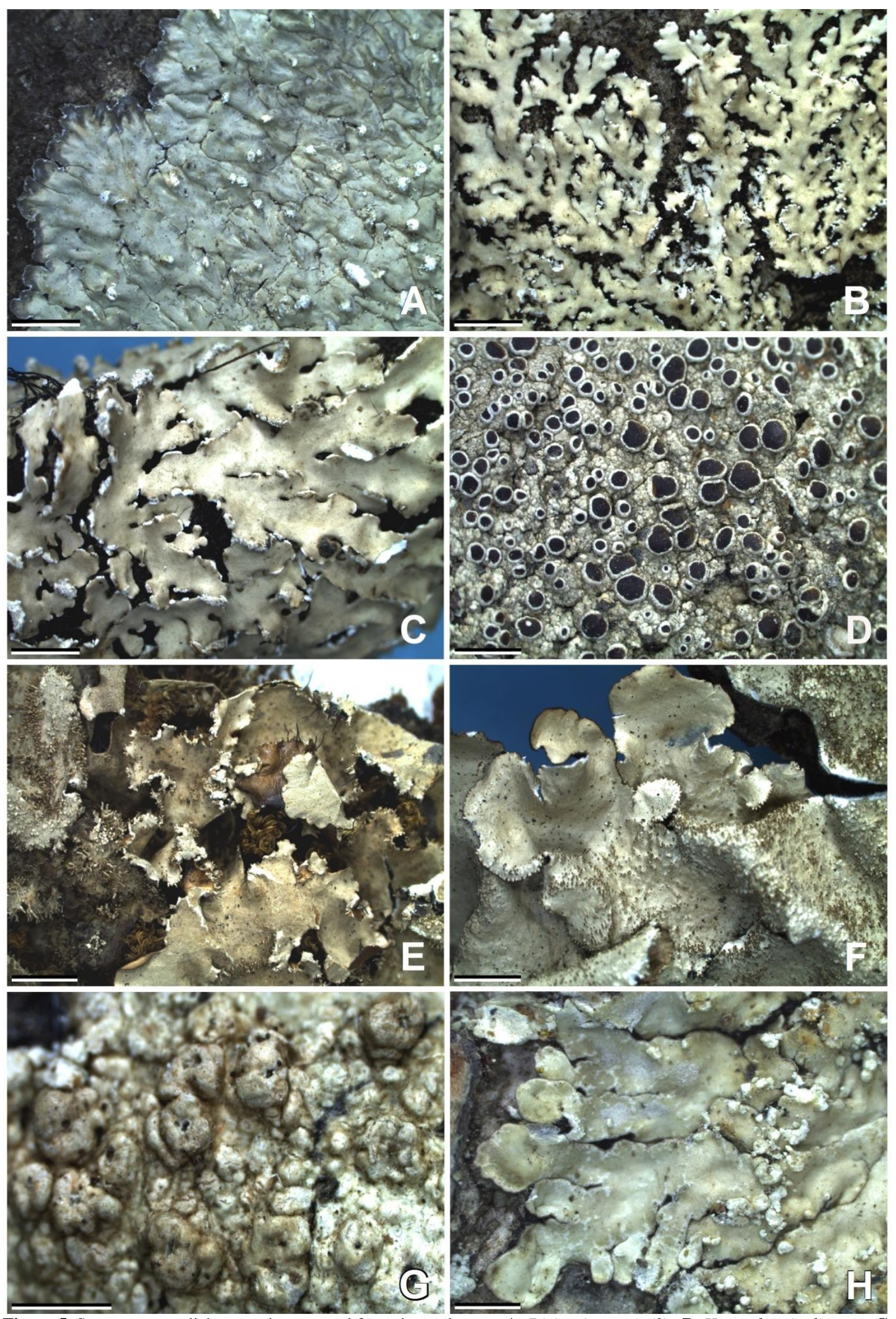

Figure 5. Some common lichen species reported from the study area: A, Dirinaria consimilis; $\mathbf{B}$, Heterodermia dissecta; $\mathbf{C}$, H. speciosa; D, Lecanora perplexa; E, Parmotrema crinitum; F, P. tinctorum; G, Pertusaria concinna; H, Pyxine coralligera. [Scale bars: A-F $=2 \mathrm{~mm} ; \mathrm{G} \& \mathrm{H}=1 \mathrm{~mm}$ ] 
plants including lichens. Unlike other epiphytes the lichens are slow growing organisms and take several years to colonize a barren habitat. The frequent firing in the Mudumalai is not giving enough time for lichens to establish on the tree trunk. However, high diversity and luxuriant growth of lichens are observed in the canopy of the forest and are collected from the fallen twigs as an example. The lichen diversity in turn indicate the healthy micro-climatic condition of the forests suitable for the growth climate sensitive plants and as well as inhabitation of animals.

\section{CONCLUSION}

Undoubtedly, the occurrence of 66 lichen species in just one ha plot clearly indicates the huge and diverse lichen reserve within the Mudumalai Sanctuary. The thorough lichen study in the area would yield many more species. The data provided in the present study will be helpful to plan and execute future lichenological studies in the area. It would be a great idea to systematically survey the 50 ha plot and quantitatively document the lichen diversity within the plot. The lichens being sensitive to micro-climatic changes such quantitative data would be helpful to monitor the effect of climate change on lichens and forest in general. The data can also be correlated with tree species and forest dynamics due herbivory by large mammals, and forest fires.

\section{ACKNOWLEDGMENTS}

We are thankful to Director, CSIR-NBRI, Lucknow for providing the laboratory facilities, to Dr. D.K. Upreti for his cooperation, to Prof. R. Sukumar, CES, IISc, Bengaluru for his kind permission to use the facilities at Mudumalai Field Station, to all members of Field Station for their cooperation during the collection.

\section{REFERENCES}

Awasthi DD (2007) A Compendium of the Macrolichens from India, Nepal and Sri Lanka. Bishen Singh Mahendra Pal Singh, Dehra Dun, India, 580 p.

Awasthi DD (1991) A key to the microlichens of India, Nepal and Sri Lanka. Bibliotheca Lichenologica 40: 337 p.

Hockings P (1989) Blue Mountains: The Ethnography and Biography of a South Indian Region. Oxford University Press, New Delhi, 406 p.

Lumbsh HT \& Huhndord SM (2007) Notes on ascomycetes, Nos. 4408-4750. Myconet 13: 59-99.

Nayaka S, Reddy AM, Ponmurugan P, Devi A, Ayyappadasan G \& Upreti DK (2013) Eastern Ghats' biodiversity reserves with unexplored lichen wealth. Current Science 104(7): 821-825.

Prabhakar R (1994) Resource Use, Culture and Ecological Change: A Case Study of the Nilgiri Hills of Southern India, Ph.D. thesis. Indian Institute of Science, Bangalore, India.

Ranganathan CR (1941) Working Plan for the Nilgiris Division. Government Press, Madras.

Satish N, Sultana S \& Nanjundiah V (2007) Diversity of soil fungi in a tropical deciduous forest in Mudumalai, Southern India. Current Science 93(5): 669-677.

Singh KP \& Sinha GP (2010) Indian Lichens, An Annonated Checklist. Botanical Survey of India, Kolkata, 571 p.

Suresh HS, Dattaraja HS \& Sukumar R (1996) Tree flora of Mudumalai Sanctuary, southern India. Indian Forester 122: 507-519.

Walker FJ \& James PW (1980) A revised guide to microchemical techniques for the identification of lichen substances. British Lichen Society Bulletin 46:13-29. 